\title{
Back to the Future: Testing different scenarios for the next Supercontinent gathering
}

Davies, Hannah; Green, Mattias; Duarte, Joao

\section{Global and Planetary Change}

Published: 01/10/2018

Peer reviewed version

Cyswllt i'r cyhoeddiad / Link to publication

Dyfyniad o'r fersiwn a gyhoeddwyd / Citation for published version (APA):

Davies, H., Green, M., \& Duarte, J. (2018). Back to the Future: Testing different scenarios for the next Supercontinent gathering. Global and Planetary Change, 169, 133-144.

\footnotetext{
Hawliau Cyffredinol / General rights

Copyright and moral rights for the publications made accessible in the public portal are retained by the authors and/or other copyright owners and it is a condition of accessing publications that users recognise and abide by the legal requirements associated with these rights.

- Users may download and print one copy of any publication from the public portal for the purpose of private study or research.

- You may not further distribute the material or use it for any profit-making activity or commercial gain

- You may freely distribute the URL identifying the publication in the public portal ?
}

Take down policy

If you believe that this document breaches copyright please contact us providing details, and we will remove access to the work immediately and investigate your claim. 


\title{
Back to the Future: Testing different scenarios for the next Supercontinent gathering
}

\author{
Hannah S. Davies ${ }^{1,2,3}$ J. A. Mattias Green ${ }^{3}$, João C. Duarte ${ }^{1,2,4}$ \\ ${ }^{1}$ Instituto Dom Luiz, Faculdade de Ciências da Universidade de Lisboa, Campo Grande, Edifício C1, Piso 1, \\ 1749-016 - Lisboa, Portugal \\ ${ }^{2}$ Departamento de Geologia, Faculdade de Ciências da Universidade de Lisboa, Campo Grande, Edifício C6, Piso \\ 4, 1749-016 - Lisboa, Portugal \\ ${ }^{3}$ School of Ocean Sciences, Bangor University, Menai Bridge, United Kingdom. \\ ${ }^{4}$ School of Earth, Atmosphere and Environment, Monash University, Melbourne, Victoria 3800, Australia

\section{Abstract}

The theory of plate tectonics and the discovery of large scale, deep-time cycles, such as the Supercontinent cycle and Wilson cycle, has contributed to the identification of several supercontinents in Earth's history. Using the rules of plate tectonic theory, and the dynamics of subduction zones and mantle convection, it is possible to envisage scenarios for the formation of the next supercontinent, which is believed to occur around $200-300 \mathrm{Ma}$ into the future. Here, we explore the four main proposed scenarios for the formation of the next supercontinent by constructing them, using GPlates, in a novel and standardised way. Each scenario undergoes different modes of Wilson and Supercontinent cycles (i.e., introversion, extroversion, orthoversion, and combination), illustrating that the relationship between them is not trivial and suggesting that these modes should be treated as end-members of a spectrum of possibilities. While modelling the future has limitations and assumptions, the construction of the four future supercontinents here has led to new insights into the mechanisms behind Wilson and Supercontinent cycles. For example, their relationship can be complex (in terms of being of the same or different order, or being in or out of phase with each other) and the different ways they can interact may led to different outcomes of large-scale mantle reorganization. This work, when combined with geodynamical reconstructions since the Mesozoic allows the simulation of the entire present-day Supercontinent cycle and the respectively involved Wilson cycles. This work has the potential to be used as the background for a number of studies, it was just recently used in tidal modelling experiments to test the existence of a Supertidal cycle associated with the Supercontinent cycle.

\section{Introduction}

The present-day Earth is currently about halfway through a Supercontinent cycle (Matthews et al., 2016), which is defined as the recurring gathering and dispersion of the continents throughout Earth's history (Nance et al., 1988). 200 Ma ago most of the continental masses were joined in a supercontinent called Pangea (Wegener, 1912). The fragmentation of Pangea led to the formation of the Atlantic Ocean 180 Ma ago. Wilson (1966) suggested that the Atlantic opened along a suture zone where another ocean once existed. This led to the concept 
of the Wilson cycle (Dewey and Spall, 1975), which describes the history of a given oceanic basin in three phases: opening and spreading, transformation of the passive margins (Atlantictype margins) into active margins (Pacific-type margins), and consumption and closure (Nance et al., 1988). The fragmentation of supercontinents always leads to the formation of internal oceans (e.g., the present-day Atlantic) and the partial consumption of the surrounding oceans (e.g., the present-day Pacific). For a new supercontinent to form, one or more oceanic basins must close. The closure of an ocean corresponds to the termination of a Wilson cycle, and the final aggregation of all (or almost all) continental masses results in the end of a Supercontinent cycle. Therefore, Wilson cycles may be of different order than, and out of phase with, Supercontinent cycles (see Duarte et al., 2018, for discussion).

There is evidence that other supercontinents existed prior to Pangea ( $250 \mathrm{Ma}$ ago; Rogers and Santosh, 2003): Pannotia ( $600 \mathrm{Ma}$ ago), Rodinia ( 1 Ga), Columbia/Nuna ( 1.7 Ga), Kenorland $(\sim 2.4 \mathrm{Ga})$ and $\mathrm{Ur}(\sim 3 \mathrm{Ga}$; see Meert, 2014 for details). This suggests a pattern of cyclicity, despite the lack of a well-defined period for the cycle (Bradley, 2011; Meert, 2014). The semantics regarding the definition of a supercontinent, and when exactly each formed and broke up, further complicates the situation (see Bradley, 2011, for a discussion). Nevertheless, since Pangea broke up around $180 \mathrm{Ma}$ ago (Scotese, 1991; Golonka, 2007) it is expected that a new supercontinent will form sometime in the future - within the next 200 - $300 \mathrm{Ma}$ (e.g., Yoshida and Santosh, 2011, 2017; Duarte et al. 2018). For this to happen, at least one present day ocean must close, but which one? Four different scenarios have been proposed to achieve this: 1) closure of the Atlantic, leading to a new supercontinent called Pangea Ultima (Scotese 2003); 2) closure of the Pacific forming Novopangea (Nield, 2007); 3) closure of both the Atlantic and the Pacific oceans, forming Aurica (Duarte et al., 2018); and 4) the closure the Arctic leading to the formation of Amasia (Mitchell et al., 2012).

The overall aim of this paper is to revisit the previously proposed scenarios to consistently simulate and standardise them using GPlates, a dedicated tectonic software (Qin et al., 2012). GPlates allows us to recreate different scenarios of supercontinent formation in parallel, allowing a direct comparison between them - including checks for advantages/plausibility and disadvantages/implausibility in each - and therefore provides new insights on how supercontinents form, how the next supercontinent will form and how supercontinents may have formed in the past.

\subsection{Main concepts}

\subsection{Supercontinent Cycles and Wilson Cycles (modes of aggregation)}

After the fragmentation of a supercontinent, the continental masses spread over the Earth's surface. For the next supercontinent to form, these masses must come together again. There are several ways in which this can happen geometrically. When a supercontinent breaks up, new Atlantic-type internal oceans must form, after which either the new internal oceans close through introversion, or the old external Pacific-type ocean which surrounds the supercontinent closes through extroversion. 
Introversion is the scenario that best illustrates a Wilson cycle. An interior ocean opens as the supercontinent breaks up. It then grows for a certain period of time - usually for a few hundred million years - after which subduction zones form at (or propagate into) the passive continental margins, leading to the closure of the basin. The supercontinent may then reform in much the same position and orientation as the preceding supercontinent. In this case, the Wilson cycle and Supercontinent cycle terminate simultaneously.

In the second mode of closure, extroversion, the external ocean closes. After the breakup of the supercontinent, the interior Atlantic-type ocean starts by expanding in much the same way as it does during introversion. However, the interior ocean does not close in on itself, but instead continues to open while the external Pacific-type ocean closes. As a consequence, the previous internal ocean becomes the new external ocean. In this scenario, the Wilson cycle of the initial internal ocean is not completed upon the formation of the supercontinent. Instead, it may only close when the new supercontinent breaks up again during the next Supercontinent cycle. This is the case with the present-day Pacific, which is the remainder of the external ocean (Panthalassa) that formed during a previous Supercontinent cycle as the result of the breakup of Rodinia 750 Ma ago (Scotese, 2009). The Pacific basin evolution is a good example of a prolonged Wilson cycle that is out of phase with the Supercontinent cycle, i.e., it forms during the break up of a supercontinent, but it does not close during the formation of the next one.

The introversion and extroversion scenarios assume that Earth only has two major oceans involved in the Supercontinent cycle, and they assume that one ocean opens and the other closes. However, if more than two oceans are present (i.e., as in the Present; see Fig. 1), other, more complex, scenarios are possible (Murphy and Nance, 2003; Duarte et al., 2018). For example, it is possible to envisage a scenario in which both the Atlantic-type and Pacific-type oceans close simultaneously (Duarte et al., 2018). This would correspond to a combination scenario (Murphy and Nance, 2003; Duarte et al., 2018). In such a case, more than one Wilson cycle may occur during the lifetime of a Supercontinent cycle.

It may also be possible to have a situation where neither the internal nor external oceans close. At least one ocean must close to facilitate supercontinental assembly, however that ocean need not be the internal or external oceans. Mitchell et al. (2012) proposes a scenario, called orthoversion, in which the Arctic Ocean closes. This leads to the next supercontinent forming $90^{\circ}$ away from the opening (rifting) point of the previous supercontinent, i.e., gathering around the North Pole.

\subsection{How do oceans start to close? The problem of subduction initiation}

To close oceans, subduction zones must form around the continental margins to recycle the oceanic lithosphere back into the mantle. While this is a fundamental and accepted aspect of the decline and eventual closure of an ocean, the question arises as to how oceans develop subduction zones? This is crucial because it may control which mode of closure a Supercontinent cycle will undergo.

New oceanic lithosphere is formed at mid-ocean ridges and then carried away as the two intervening plates drift apart. When new lithosphere forms it is hot and more buoyant than the 
underlying asthenosphere. As it ages and cools, the oceanic lithosphere eventually becomes denser than the asthenosphere and thus negatively buoyant; this occurs $\sim 10 \mathrm{Ma}$ after it forms (Cloos, 1993). Consequently, the lithosphere slightly sags into the mantle, forming deep abyssal plains. In an Atlantic-type ocean, oceanic plates are attached to mid oceanic ridges and continental blocks (both of which are buoyant), preventing the lithosphere from starting to sink into the mantle - a requirement for an ocean to close. Notwithstanding, observations show that on the present-day Earth there is almost no oceanic lithosphere older than $200 \mathrm{Ma}$ (Muller et al., 2008; Bradley, 2008). The exception is a portion of $350 \mathrm{Ma}$ old oceanic lithosphere in the Herodotus basin west of Cyprus (Granot, 2016). Furthermore, after investigating 76 ancient passive margins, Bradley (2008) concluded that they had an average lifespan of $178 \mathrm{Ma}$ and only 5 of them had a lifespan of over $350 \mathrm{Ma}$. This suggests that, somehow, subduction zones must form at passive margins before they reach 200-300 Ma. However, as oceanic lithosphere cools, it also becomes stronger. Calculations show that there are no forces at passive margins to start a subduction spontaneously, i.e., oceanic lithosphere foundering due to its own weight (see Stern and Gerya, 2017 and references therein). If oceanic lithosphere does not spontaneously subduct, a paradox develops: how do subduction zones form at passive margins of pristine Atlantic-type oceans?

It has been proposed that instead of starting spontaneously (due to their own weight), subduction zones can propagate from ocean to ocean or be forced by stresses transmitted from nearby subduction and/or collision zones (Duarte et al., 2013; Stern and Gerya, 2017). We can thus think of subduction initiation as a sort of invasive or infectious mechanism (e.g., Mueller and Phillips, 1991; Scotese, 2003; Duarte et al., 2018). In fact, there are already two fully developed subduction zones in the Atlantic, the Scotia and the Lesser Antilles arcs, that seemed to have been propagated from, or induced by, subduction zones in the Pacific Ocean (see Fig. 1). However, the exact mechanism by which they developed is still debated (see e.g., Eagles and Jokat, 2014 and Wright and Wyld, 2011). A third place where this may be happening is in the Gibraltar Arc (Duarte et al., 2013). In this case, the subduction system is migrating from the Mediterranean into the Atlantic. Moreover, it is possible that if subduction zones do not invade an ocean over timescales of $200-300 \mathrm{Ma}$, some sort of weakening mechanism can come into play (e.g., hydration of oceanic lithosphere; Duarte et al., 2018) and thus start subduction. Note that even though oceanic lithosphere must be consumed within $200-300$ $\mathrm{Ma}$ after it forms, the ocean basin can exist on the surface of the Earth for longer (e.g., the present-day Pacific; Bradley, 2008). This can happen if a balance between spreading ridges and subduction zones enter a quasi-steady state (e.g., as happened for the Panthalassa or Pacific Ocean (Scotese, 2009)). However, it can be argued that such a quasi-steady state would not last for longer than 600 - 700 Ma because ridges will eventually be subducted (Thorkelson, 1996).

\subsection{Plate tectonics and mantle convection}

Wilson cycles, Supercontinent cycles, and their associated processes, are an expression of plate tectonics and mantle convection. Plate tectonics is sometimes portrayed as the unifying theory of solid Earth. It describes the Earth's surface as being composed of several independently moving lithospheric plates, which incorporate the crust and a part of the upper mantle (lithospheric mantle; e.g., Wilson, 1965; Mckenzie and Parker, 1967; Le Pichon, 1968). The 
present-day velocities of each of the major plates are well known and illustrated in, e.g., Schellart et al., (2007), even though there is some debate about which reference frame is best (Schellart et al., 2008).

Recently, a more dynamic view of plate tectonics has emerged, which not only incorporates the useful kinematic description but also its driving and resisting mechanisms/forces (see Schellart and Rawlinson, 2010 and references therein). It is now relatively accepted that the main driver of the plates' movement is the slab pull force of sinking lithosphere as it sinks into the mantle and, the less efficient, ridge push - a force arising from the differential of potential energy across the oceanic lithosphere. Recently, it has been proposed that plumes can also exert and additional lateral push on the plates (e.g., Cande and Stegman, 2011; Iaffaldano, et al., 2018). Such plume push may only have a relatively localized effect, though it can have an important role during the break-up phase of supercontinents. This new dynamic framework also implies that plate tectonics is not an independent system with plates floating as solid crust on a boiling pot (the mantle), but that tectonic plates should actually be considered a part of a larger mantle circulation system that is cooling and convecting (i.e., as a cooler part of the fluid inside the pot). In this system, part of the material is heated from within, although there are still two thermal boundaries: one hot at the bottom of the mantle (near the core-mantle boundary) that generates upwelling zones and plumes and another cold at its surface (the lithosphere) where downwelling zones form (subduction zones).

A simple explanation of mantle circulation is as follows. Material in the mantle is heated from within but also at the core-mantle boundary layer. Here, less dense hot material accumulates, which begins to rise in upwellings due to thermal buoyancy. This material eventually rises through the mantle, feeding mid-ocean ridges and forming oceanic lithosphere. The oceanic lithosphere then remains at the surface for a few hundred million years before eventually being subducted and sinking back into the mantle as cold and dense lithospheric slabs, eventually cascading back to the core-mantle boundary. These slabs may carry lighter chemical compounds that will provide an additional chemical buoyancy to the material that accumulates in this lower layer and helping to kick-start the next mantle upwelling.

In the present-day Earth's mantle there are two major regions of upwelling and two of downwelling that roughly define two convective systems (with four cells). Using seismic tomography, two areas with low shear-wave velocity anomalies below the Atlantic (the Tuzo upwelling) and the Pacific (the Jason upwelling) have been identified (e.g., Torsvik et al., 2016). The anomalies have been interpreted as regions of low density/high temperature that seem to correspond to hot ascending material, and they are referred to as Large Low Shear Velocity Provinces (LLSVPs). In turn, there are two major downwellings composed of descending slabs in the Eastern and Western Pacific margins (the Andean/Cascadia and the Marianas/Japan/Tonga subduction systems, respectively). These are also well imaged in tomography data as (high shear-wave velocity) anomalies, which correspond to cold/dense material.

At present, the plates are driven by these descending slabs of dense oceanic lithosphere, while the two major upwellings feed or have fed the Atlantic and Pacific mid-ocean ridges. For example, the break-up of Pangea may have been caused by one of these upwellings penetrating 
through the continental crust and initiating the formation of the Atlantic (Murphy et al., 2009; Torsvik et al., 2010). However, some ridges seem to be offset from the upwelling regions, meaning that these ridges may presently be passive and fed by upper mantle material. Moreover, it is also recognized today that the ascending material does not correspond to the classic idea of mantle plumes. Instead, the position of the plumes may be controlled by the aforementioned upwellings: mantle plumes seem to be generated at the boundaries of these upwellings. These boundaries are known as plume generation zones (PGZs; Burke et al., 2008) and the plumes generated there feed the majority of hotspots on Earth (Torsvik et al., 2016). Understanding of the formation, behaviour, and tenure of these LLSVPs and PGZs will be crucial in the determination of their role in the breakup of supercontinents and the maintenance of oceans (Boschman and van Hinsbergen, 2016).

\subsection{Methodology}

Because of an abundance of previous investigations into past supercontinents and cycles (Rogers and Santosh, 2003; Murphy and Nance, 2003; 2005; Bradley, 2011; Merdith et al., 2017; see Table 1), we have gained an insight on how supercontinents form and evolve. Furthermore, since we know that there was a somewhat regular pattern in the disaggregation and formation of past supercontinents, it is reasonable to assume that this pattern may repeat itself in the future. Although there are a number of predictions about the future supercontinent (e.g., Hoffman, 1999), with many nuances, we choose to present here the four potential scenarios that illustrate the main modes of oceanic closure and supercontinent formation described in Section 2.1. Each of these predictions independently reaches supercontinent accretion within the next $300 \mathrm{Ma}$, highlighting that we are close to the mid-point of the current Supercontinent cycle. The four explored scenarios, along with past supercontinents are summarised in Table 1.

Table 1. A complete list of all the supercontinents believed to have existed during the period of active plate tectonics on Earth up to the present-day and their modes of formation, along with the four scenarios of the formation of the next supercontinent.

\begin{tabular}{|l|l|l|l|}
\hline \multicolumn{1}{|c|}{ Supercontinent } & \multicolumn{1}{|c|}{ Tenure (Ma) } & Mode of formation & \multicolumn{1}{|c|}{ Supporting references } \\
\hline Ur & $\sim 3000 \mathrm{Ma}$ ago & Not known & $\begin{array}{l}\text { Rogers and Santosh } \\
(2003)\end{array}$ \\
\hline Kenorland/Superia/Sclavia & $\sim 2500 \mathrm{Ma}$ ago & Not known & Meert (2014) \\
\hline Columbia/Nuna & $\begin{array}{l}1800-1500 \mathrm{Ma} \\
\text { ago }\end{array}$ & Introversion & $\begin{array}{l}\text { Rogers and Santosh } \\
(2003) ; \text { Murphy and } \\
\text { Nance (2003) }\end{array}$ \\
\hline Rodinia & $\begin{array}{l}1100-800 \mathrm{Ma} \\
\text { ago }\end{array}$ & Extroversion & $\begin{array}{l}\text { Merdith et al. (2017); } \\
\text { Dalziel et al. (2000); } \\
\text { Murphy and Nance (2003) }\end{array}$ \\
\hline $\begin{array}{l}\text { (Greater) } \\
\text { Gondwana/Pannotia }\end{array}$ & $\begin{array}{l}650-560 \mathrm{Ma} \\
\text { ago }\end{array}$ & $\begin{array}{l}\text { Extroversion/ } \\
\text { Orthoversion }\end{array}$ & $\begin{array}{l}\text { Merdith et al. (2017); } \\
\text { Murphy and Nance (2005) }\end{array}$ \\
\hline
\end{tabular}




\begin{tabular}{|l|l|l|l|}
\hline Pangea & $\begin{array}{l}250-180 \mathrm{Ma} \\
\text { ago }\end{array}$ & $\begin{array}{l}\text { Introversion/ } \\
\text { Orthoversion }\end{array}$ & $\begin{array}{l}\text { Golonka (2007); Murphy } \\
\text { and Nance (2005); } \\
\text { Mitchell et al. (2012) }\end{array}$ \\
\hline Pangea Ultima & $\begin{array}{l}+250 \mathrm{Ma}- \\
\text { Distant future }\end{array}$ & Introversion & $\begin{array}{l}\text { Scotese (2003); Yoshida } \\
\text { and Santosh (2017) }\end{array}$ \\
\hline Novopangea & $\begin{array}{l}+200 \mathrm{Ma}- \\
\text { Distant future }\end{array}$ & Extroversion & $\begin{array}{l}\text { Nield (2007); Yoshida } \\
\text { and Santosh (2017) }\end{array}$ \\
\hline Aurica & $\begin{array}{l}+250 \mathrm{Ma}- \\
\text { Distant future }\end{array}$ & Combination & $\begin{array}{l}\text { Duarte et al., (2018); } \\
\text { Yoshida and Santosh } \\
(2017)\end{array}$ \\
\hline Amasia & $\begin{array}{l}+200 \mathrm{Ma}- \\
\text { Distant future }\end{array}$ & Orthoversion & $\begin{array}{l}\text { Mitchell et al. (2012); } \\
\text { Yoshida and Santosh } \\
\text { (2017) }\end{array}$ \\
\hline
\end{tabular}

All the explored future scenarios were proposed independently at different times by different authors (see Table 1). Because of this, each of the scenarios have their own details and were originally explored using different space and time scales. There is therefore an issue when comparing the scenarios because they are not standardised and do not necessarily resolve the same time periods. For example, the prediction of the future; Pangea Ultima by Scotese (2003) is presented at time slices for 50, 100 and $250 \mathrm{Ma}$ into the future, whereas Aurica by Duarte et al. (2018) is presented for 20, 150 and $300 \mathrm{Ma}$. Consequently, direct comparisons between each scenario for specific time slices is difficult, and to compare the future scenarios directly, we need to standardise them with respect to projections and time slices investigated. This is the main aim of this paper.

242 Consequently, we will reproduce all four scenarios for the formation of the next supercontinent in a standardised environment using a state-of-the-art software that allows the kinematic manipulation of tectonic plates and continents - GPlates (Qin et al., 2012; see https://www.gplates.org/ for the original files. The modified files with our different scenarios are provided as supplementary material). GPlates can be used for a number of different types of tectonic and geodynamical modelling endeavours, e.g., to visualise geolocations, as boundary conditions for geodynamical modelling, to reconstruct plate motions (kinematics), or to visualise predictions of the tectonic future of the Earth. The software is able to move plates and continents through time using editable rotation files, enabling joining kinematic and geodynamic (conceptual) models. These models can be exported from the GPlates program in a large number of formats compatible with other GIS software, or simply as images presented in various widely used planetary map projections. The data we provide in the supplementary material supports all these features.

255 For our study, continental lithospheric extents were taken from Matthews et al. (2016), imported from the GPlates user database. Subduction zones and ridge extents were then drawn in as schematic geological features in GPlates. Therefore, all geological features included in this work were annotated in GPlates with timings, plate id's and descriptions. The models created do not explicitly incorporate continental deformation, but allow some overlap between 
continents, which somewhat mimics intercontinental deformation. We also did not simulate continental accretion or erosion (e.g., forearc accretion or erosion at subduction zones).

Each of the scenarios was modelled from the same initial geometric conditions shown in Fig 1. Between 0 and $25 \mathrm{Ma}$, the continents follow present-day drift velocities based on Schellart et al., (2007). Rotation files for each of the scenarios using these velocities were written as a tab delimited text file readable by GPlates. After $25 \mathrm{Ma}$, each scenario was constructed as faithfully as possible to the original published work. To do this, we have visually moved the continental blocks to their future locations based on each author's construction. When manually manipulating the continents, GPlates then automatically writes those instructions to the rotation files. Note that then GPlates can provide scenarios that are continuous in space and time (see supplementary material). However, these continuous animations only show the continental blocks. The positions of ridges and subduction zones are not animated and were only drawn in schematically for specific time slices (Figs. 2-5).

The computed velocities for each continental block in each scenario are provided in Table 2. The average velocities, $3.9 \mathrm{~cm} \mathrm{yr}^{-1}$, are close to the paleo Meso-Cenozoic plate velocities reported in Young et al. (2018), though slightly lower (in particular Amasia). This means that the timing of the next supercontinent accretion may be overestimated in all the scenarios (see Discussion).

Table 2. Average velocities in $\left(\mathrm{cm} \mathrm{yr}^{-1}\right)$ for each of the major continents in each scenario, and total average plate velocity for each of the scenarios.

\begin{tabular}{|l|c|c|c|c|}
\hline & Pangea Ultima & Novopangea & Aurica & Amasia \\
\hline Africa & 4.5 & 3.9 & 7.9 & 1.4 \\
\hline Australia & 6.2 & 4.5 & 1.8 & 6.0 \\
\hline East Antarctica & 3.7 & 4.9 & 2.9 & 0.2 \\
\hline East Asia & N/A & N/A & 0.8 & N/A \\
\hline Eurasia & 4.2 & 3.8 & 7.7 & 0.6 \\
\hline Greenland & 2.3 & 3.0 & 4.3 & 0.6 \\
\hline North America & 4.0 & 3.4 & 4.0 & 0.8 \\
\hline Somalia plate & N/A & 6.5 & N/A & N/A \\
\hline South America & 5.5 & 5.8 & 5.5 & 5.3 \\
\hline West Antarctica & 6.0 & N/A & N/A & N/A \\
\hline Average Total & 4.5 & 4.5 & 4.4 & 2.1 \\
\hline
\end{tabular}

\subsection{Back to the Future}

\subsection{Introversion: Pangea Ultima}

Pangea Ultima is an introversion scenario in which the Atlantic Ocean closes in an asymmetrical fashion (Scotese, 2003). This is because it is assumed that the two already existing subduction zones in the Atlantic will propagate along the Eastern margins of the 
large subduction system develops, possibly in the next 25-50 Ma (see Fig. 2a and Pangea Ultima animation in the Supplementary Files). During this period Africa continues to move north and fully collides with Eurasia forming the mega-continent Eurafrica, whereas the Americas and Eurafrica continue to drift apart.

After $50 \mathrm{Ma}$, although the new Atlantic subduction system is fully developed, the Atlantic midocean ridges may continue to spread, delaying the point at which the bordering continents start to converge. Therefore, the Atlantic continues to open until $100 \mathrm{Ma}$ because the mid-Atlantic ridge continues to produce oceanic lithosphere that can compensate lithospheric consumption at subduction zones. The lithosphere lying on the Western side of the ridge is eventually subducted whereas the lithosphere on the Eastern side of the ridge is not, as it is attached to the passive margins of the Eurafrican mega-continent. By this time, Australia has collided with South-East Asia terminating the Mariana trench and a small portion of the Pacific Ocean. Antarctica has also begun to drift north into the Indian Ocean basin (see Fig. 2b).

By 100 Ma the mid-Atlantic ridge starts to undergo subduction at the East American subduction zones (Fig. 2b). This marks the midpoint of the Atlantic Wilson cycle because with the subduction of the ridge, the ocean can no longer continue to open and must close. At this point, Antarctica has rifted into two separate parts generating a small actively spreading new ocean. East Antarctica is still drifting north closing the southern Indian Ocean. However, the western Antarctic fragment remains in the Southern Ocean, following the same path as East Antarctica but at a significantly slower rate because of the spreading of the new Trans-Antarctic Ocean.

In $200 \mathrm{Ma}$, the Atlantic Ocean will be partially closed. South Africa is now less than a 1000 $\mathrm{km}$ from South America (Fig. 2c). The subduction of the Mid-Atlantic ridge, the advanced age of the Atlantic oceanic lithosphere, the propagation of subduction zones to the southern tip of Africa, and the generation of a new meridional spreading centre in the Arctic and Pacific Ocean all contributed to a rapid closure of the Atlantic Ocean. Antarctica has also started to reform at this time. The trans-Antarctic ocean was very short lived: when it ceased spreading, the Antarctic fragments could reunite as they combined with Indonesia, shutting down the Sumatra subduction zone in the process.

In $250 \mathrm{Ma}$, Pangea Ultima has formed, with a remnant of ancient Indian and Atlantic Ocean forming an inland sea of the supercontinent. At this time, an almost complete ring of subduction zones surrounds the supercontinent. Because the coasts of Pangea Ultima are the remnants of the coast of the Pacific Ocean, it has formed over the Tuzo LLSVP.

In Pangea Ultima the Supercontinent cycle and the Wilson cycle are in phase for the Atlantic (Fig. 2e). The new Antarctic Ocean formed develops a Wilson cycle out of phase with the Supercontinent cycle however, as it does not fully close with the formation of Pangea Ultima. Fig. 2e also shows that the Pacific remains the dominant ocean for the duration of the scenario despite the other oceans presented growing and shrinking over the 500 Ma presented in Fig. $2 \mathrm{e}$.

\subsection{Extroversion: Novopangea}


Novopangea is an extroversion scenario in which the Pacific Ocean closes. It is based on the fact that the Pacific is an old oceanic basin (older than Pangea) surrounded by subduction zones that are presently converging (Hatton, 1997; Murphy and Nance, 2003). Conversely, the present-day Atlantic is a new ocean and home to the largest mid-ocean ridge on Earth and only a few short subduction zones that may not develop into a large-scale subduction system (Dalziel et al., 2013; Stern and Gerya, 2017). Therefore, the continents will continue to drift apart for the next $200 \mathrm{Ma}$ in roughly the same directions as present-day, but at slightly faster speeds (see Schellart et al., 2008 for details). The East African rift system will also continue to develop, eventually becoming an ocean basin that replaces the Indian Ocean. See Fig. 3 and the Novapangea animation in the Supplementary Files for the illustrations related to the description below.

In $50 \mathrm{Ma}$, the Pacific Ocean will be a series of seaways between Asia, Australia, Antarctica and the Americas. The northward drift of Australia and Antarctica, together with the convergent drift of Asia, and the Americas due to the continued opening of the Atlantic, reduces the area of the Pacific Ocean. Conversely, the highly active Mid-Atlantic ridge, combined with the closure of the Pacific and little to no subduction in the Atlantic, allows it to grow quickly; by $50 \mathrm{Ma}$, the Atlantic Ocean is over three times its present-day width. Some subduction zones have developed at the basin's edges, particularly along the West coast of Europe and Northwest Africa (Duarte et al., 2013). The opening of the East African Ocean has already started and is in a similar state to the Red sea at present. The Red Sea and the Mediterranean, however, have both closed after $50 \mathrm{Ma}$.

In $100 \mathrm{Ma}$, the Pacific is mostly closed, except for an area west of South America (Fig. 3b). The Atlantic has continued to open, as has the East African Ocean. However, the almost complete closure of the Indian and Pacific Ocean basins, and the near complete assembly of Novopangea, means that the Atlantic can no longer continue to open. The closure of the Pacific Ocean also shuts down a significant length of subduction zones. However, because of the way that the Indian Ocean closes and the development of the subduction zones in the Atlantic Ocean, the planet retains a considerable extent of subduction zones throughout (See Fig. 3d).

By 150 Ma the Pacific is nearly closed, with very little oceanic lithosphere left (Fig. 3b-c). The ongoing continental collisions between the Americas and Eastern Asia will likely slow down oceanic closure, much like the Mediterranean is doing today. During this time the northern portion of the Indian Ocean is almost fully recycled as consequence of the migration of the Somalia plate towards the Sumatra subduction zone and the continued opening of the East African Ocean (Fig. 3c). At this point, the Atlantic has developed a large-scale subduction system. Some of these subduction zones may also propagate into the margins of the East African Ocean.

In $200 \mathrm{Ma}$, Novopangea is fully formed; Somalia and Madagascar have closed the majority of the Northern Indian Ocean, and the Pacific Ocean has completely closed leaving the Atlantic to be the surrounding ocean of the supercontinent (Fig. 3d).

The closure of the Pacific leads to the elimination of a large amount of subduction zones, and if new subduction systems do not develop promptly in the ocean surrounding the 
supercontinent (i.e., the Atlantic), Earth may undergo a period of tectonic quiescence (see Silver and Behn, 2008). However, new subduction zones are invading the Atlantic (Duarte et al., 2013; 2018), and it is therefore likely that when Novopangea forms, these subduction systems have already propagated along the margins of the Atlantic and eventually of the Eastern African Ocean. The Sumatra subduction system may also propagate into the Eastern African Ocean as the collision of the Somalia block may not fully shut this system down.

Novopangea forms over the Jason LLSVP. The closure of the Pacific Ocean marks the end of its Wilson cycle, which in this case lasted for over a billion years (Scotese, 2009; Merdith et al., 2017), from the breakup of Rodinia 750 Ma ago to the formation of Novopangea. The Pacific Ocean (and the former Panthalassa Ocean) thus persisted over several full Supercontinent cycles. This is a special case in which the ocean's Wilson cycle is in phase with, but of different order than, the Supercontinent cycle. Note, however, that even though the Pacific (and Panthalassa) basins were long-lived, its oceanic lithosphere underwent several phases of renewal (Boschman and van Hinsbergen, 2016).

\subsection{Combination: Aurica}

Aurica is a combination scenario where both the Atlantic and Pacific oceans close. Such conjecture is based on the fact that both the Atlantic and the Pacific oceans already have portions of oceanic lithosphere with ages close to $200 \mathrm{Ma}$, and the average age of the presentday oceanic lithosphere is around $60 \mathrm{Ma}$, with only a few regions older than this (Muller et al., 2008). Moreover, during Earth's history, oceanic lithosphere older than a few hundred million years can hardly persist at its surface (Bradley, 2011). This is consubstantiated by the observation that subduction zones are propagating into and inside the Atlantic, meaning that, similarly to the Pacific, the Atlantic may be fated to close. To achieve this, at least one new ocean must be created. In this scenario, a large intracontinental rift develops along the border of India and Pakistan between the Eurasia and several East Asian tectonic blocks/subplates, which propagates along the Himalaya and through the Baikal rift and Kamchatka plate boundary forming the Pan-Asian Ocean (see Fig. 4, the Aurica animation in the Supplementary Files, and Duarte et al., 2018).

In $50 \mathrm{Ma}$, subduction zones have propagated in the Atlantic (Fig. 4a). However, a balance between spreading and consumption allows it to continue to open for some time. The Pacific accelerates its closure due to the continued subduction of the East Pacific rise and the now fully developed Pan-Asian Rift. Furthermore, much like in the extroversion scenario described in section 3.2, Antarctica continues drifting north into the Pacific Ocean, contributing to the ocean's closure. At this time, Australia has fully collided with the Eastern Asian continent.

In $100 \mathrm{Ma}$, both the Atlantic and the Pacific spreading centres have been subducted (see Fig. 4b), meaning that they can no longer compensate consumption at subduction zones. The PanAsian Ocean becomes the largest ocean on Earth, while the Pacific and the Atlantic have closed significantly. At this point, Antarctica also starts to collide with the Eastern Asian continent. Subduction zones have now formed in the two Atlantic margins, leading to an Atlantic "ring of fire". 
Fig. 4c shows the 200 Ma time slice, in which the Pacific has fully closed, and the Atlantic is entering a terminal stage of closure. The Pan-Asian Ocean continues to open and is fully merged with the former Indian Ocean. At this point, it is almost fully surrounded by passive margins, with the exception of the Sumatra subduction system that may propagate into the PanAsian basin with time.

By $250 \mathrm{Ma}$, the Atlantic has completely closed forming Aurica surrounded by the Pan-Asian Ocean (Fig. 4d). Aurica forms near the antipodes of Pangea, precisely over the Jason LLSVP. A large-scale subduction system does not fully form around the continent, potentially leading to a period of tectonic quiescence. Nevertheless, subduction systems such as Sumatra can propagate along Aurica's margins re-establishing plate recycling rates to that of normal functioning of plate tectonics.

This scenario involves the termination of the Wilson cycles of the Atlantic and the Pacific, and the beginning of the one for the Pan-Asian Ocean (see Fig. 4e). The Aurica scenario thus involves two Wilson cycles in phase with the Supercontinent cycle, although the Atlantic one is of same order and the Pacific one of different order to the Supercontinent cycle, whereas the Pan-Asian Wilson cycle is out of phase with the Supercontinent cycle.

\subsection{Orthoversion: Amasia}

In the orthoversion scenario the new supercontinent forms by the closure of the Arctic Ocean (Mitchell et al., 2012). This is based on the rationale that supercontinents form at $90^{\circ}$ from the previous supercontinent because of a bias on the mantle structure left by the preceding supercontinent. Pangea's subduction zones left a remnant volume of downwelling mantle, a "ring of slabs", that may confer a positive bias in plate drift towards a segment of this ring. Also, according to the present-day drift of the continents, it is likely that they will (on large scales) continue moving north.

In $50 \mathrm{Ma}$, the Mediterranean, Arctic, and part of the East China and Philippine seas have been closed by the collision of Africa with Eurasia, Asia with the Americas and Australia with East China, respectively (see Fig. 5a and the Amasia animation in the Supplementary Files). Subduction zones propagate along the margins of the Atlantic and Indian oceans, and the MidAtlantic ridge has lost some of its northern extent. The Americas split, temporarily forming a new gateway between the Pacific and Atlantic oceans.

In $100 \mathrm{Ma}$, South America begins rotating clockwise, pulled by the Peru-Chile trench (Fig. 5b). This drift represents the only major large-scale reorganisation of continental lithosphere; all other continents, with exception of Antarctica, experience only slow northward drift. Subduction zones continue to propagate along the Antarctic, African, South American and the East Asian margins, while a southern hemisphere ridge system becomes dominant.

In $150 \mathrm{Ma}$, the Northern Atlantic and the Pacific Ocean have partially closed due to the aggregation of the continents around the North Pole and the continued rotation of South America. At this point, Australia collides with Asia closing the Sea of Okhotsk (Fig. 5c). 
In $200 \mathrm{Ma}$, Amasia has formed by aggregating all continental masses except Antarctica as South America completes its rotation and collides with North America (Fig. 5d). Note that in this scenario oceans containing old lithosphere, such as the Pacific, the Atlantic, and the Indian oceans, do not close. Therefore, it is likely that a large-scale subduction system develops along the southern margins of Amasia, and along the coasts of Antarctica.

This is also the only supercontinent that does not form over a present-day LLSVP. However, it is debatable if LLSVPs persist in the same region over large periods of time, or if they are rearranged as a function of the reorganization of plates and continents (Torsvik et al., 2010). Also, because Antarctica remains near its current location Amasia is technically not a complete supercontinent (Bradley, 2011).

In the orthoversion scenario, the Atlantic and the Pacific Wilson cycles do not terminate with the formation of the supercontinent, and the Arctic Ocean undergoes a short Wilson cycle (see Fig. 5e). All the Wilson cycles are out of phase with the Supercontinent cycle.

\section{Analysis}

\subsection{Pangea Ultima}

Pangea Ultima is an introversion scenario, i.e., the interior ocean (the Atlantic) will close and "Pangea" will reform more or less in the same position as the previous supercontinent. In this scenario, the Atlantic takes $\sim 280$ Ma to open and $\sim 150$ Ma to close. This makes sense because once subduction zones are introduced into an ocean the plates and the adjacent continents may start moving faster, $c . f$., for example the present-day plate velocities of the plates containing the Atlantic $\left(\sim 15 \mathrm{~mm} \mathrm{yr}^{-1}\right)$ and the Pacific plate $\left(\sim 100 \mathrm{~mm} \mathrm{yr}^{-1}\right.$; Forsyth and Uyeda 1975; Muller et al. 2008). Consequently, Wilson cycles do not need to be time symmetric.

Introversion scenarios are known to have occurred before on Earth (Murphy and Nance, 2008). For example, most of Pangea formed via introversion, closing the Rheic and the Iapetus oceans (Stampfli and Borel, 2002; Nance et al., 2012). It has been proposed that this was actually the result of the existence of a geoid high in the Panthalassa Ocean that would not allow continents (and subduction zones) to pass over it (Murphy and Nance, 2003; 2005). We now know that this geoid high is actually the result of a large mantle upwelling associated with the Jason LLSVP (Torsvik et al., 2016). However, this LLSVP may move over long geological time scales (Murphy and Nance, 2008). Furthermore, in the introversion scenario the newly formed Atlantic subduction zones (i.e., mantle downwellings) do not fully cross either of the presentday mantle upwellings. This means that neither of the present-day mantle convective systems would shut down.

\subsection{Novopangea}

Novopangea forms by extroversion, roughly at the antipodes of Pangea. The supercontinent will start forming in roughly $200 \mathrm{Ma}$, meaning that at present, we are slightly before the midpoint in this Supercontinent cycle scenario. This makes sense because we are at a period of almost maximum dispersion, but the Atlantic is still smaller than the Pacific. In this case the timing of the Supercontinent cycle is simply controlled by the average velocity of plates and 
the Earth's diameter. In this scenario, the ocean would be near a steady-state in much the same way that the Panthalassa Ocean may have been in the past. Furthermore, some kind of ocean resurfacing, either by the occurrence of small internal Wilson cycles or the creation of new oceanic ridges could occur (Stampfli and Borel, 2002; van der Meer et al., 2012; Boschman and van Hinsbergen, 2016).

In the Novopangea scenario the new supercontinent forms right on top of the Jason LLSVP/Upwelling. This means that the two subduction systems on either side of the Pacific, both of which are major downwellings, will have to move towards, and overlap with, this first order upwelling. This would probably lead to the cessation of one of the two principal mantle convection systems.

Some component of extroversion is known to have occurred in past cycles, e.g., when going from Rodinia to Pangea (Murphy et al., 2009). However, Pannotia is sometimes mentioned as a supercontinent that existed in between Rodinia and Pangea, and therefore Pangea kept elements of both introversion and extroversion (see Murphy and Nance, 2003). This makes it clear that both introversion and extroversion should be regarded as end members and that Supercontinent cycles can have both introversion and extroversion components. For example, some internal oceans may close while some continental blocks go around the Earth to close portions of external oceans.

\subsection{Aurica}

Aurica is a combination scenario, in which both an interior ocean (Atlantic) and an exterior ocean (Pacific) close. Here, the Pan-Asian ocean will become the external (super) ocean of the next Supercontinent gathering. This is plausible if we take into account that the Eurasian continent did not yet fully break along the major suture zones that define its major cratons; and it is known that several rift systems are developing and defining a broad deformation zone between the north Indian Ocean and the Artic Rift (e.g., the Baikal Rift). Also, Africa is also presently undergoing break up along the East African Rift, which may eventually link up with the Pan-Asia rift. One of the characteristics of this scenario is that it eliminates most of the old Atlantic and Pacific oceanic lithosphere, and if the new African Rift develops it would also allow the partial elimination of the present-day Indian Ocean.

Combination scenarios are likely to occur because when a supercontinent breaks up and gathers again, several continental blocks are dispersed around the Earth leaving behind several interior oceans. Some of these blocks may come together again via introversion, while others can travel around the Earth closing portions of the external oceans. This may have been the case of the previous Supercontinent cycle as Pangea seems to have preserved both elements of introversion and extroversion, because Pannotia/Gondwana (which formed by extroversion) aggregated with the remaining continents to form Pangea by introversion (Murphy and Nance, 2003).

In this scenario, once subduction zones are introduced in the Atlantic, two new major mantle downwellings will develop. This may cause the Earth to temporarily have three main convection systems. However, while the Pacific Ocean closes, two downwellings (corresponding to the Western and Eastern Pacific subduction zones) will converge and move 
over the Jason upwelling, which may cause the termination of the present-day Pacific convective system in around $100 \mathrm{Ma}$ (Fig. 4b). After $200 \mathrm{Ma}$, the two newly formed Atlantic downwellings will also move over Jason (see Fig. 4c). The Earth may then be, for a short time, in a one convection system mode. However, once the new supercontinent is fully formed (in $250 \mathrm{Ma}$ ) major subduction systems will likely form around it, with one big upwelling in the external Pan-Asia Ocean and another forming in the interior of the Supercontinent (see Fig. $4 d)$.

\subsection{Amasia}

Amasia is an Orthoversion scenario, in which the continents re-join at $90^{\circ}$ from the previous supercontinent. As consequence, both the Atlantic and Pacific oceans will, by the time of supercontinent aggregation, have an age of $\sim 1 \mathrm{Ga}$ and $\sim 400 \mathrm{Ma}$, respectively. This implies that these oceans may have to undergo some form of lithospheric resurfacing, eventually by the creation of new rifts (Boschman and van Hinsbergen, 2016). According to Mitchell et al., (2012), Pangea formed by orthoversion and that lead to the full reorganization of mantle cells. In fact, in our simulation, Amasia forms away from the two present-day major mantle upwellings (Fig. 5d), but it is uncertain how the mantle structure will respond to such continental evolution and configuration. Also, the phase relation between Supercontinent cycle and Wilson cycle also loses its strict meaning suggesting that much of the terminology used is simply an idealization (but a useful one, nonetheless).

It is also worth noting that a first attempt of dynamically modelling the evolution of the presentday Supercontinent cycle using mantle convection models shows a strong component of orthoversion (Yoshida, 2016), although other features, e.g., subduction initiation in the Atlantic, are not taken into account. If they had been other components of extroversion or introversion would probably have occurred (see Yoshida, 2016, for details).

\subsection{Ocean divergence and convergence rates}

In Table 2 we present the drift velocities of the continental blocks in each scenario. With the values in Table 2, and other data from GPlates, we were able to calculate the rates of divergence and convergence for each of the oceans in each scenario (see Fig. 6). In the Pangea Ultima scenario the divergence rate of the Pacific Ocean is around $6.8 \mathrm{~cm} \mathrm{yr}^{-1}$, which is approximately the convergence rate at which the Atlantic closes $\left(6.3 \mathrm{~cm} \mathrm{yr}^{-1}\right)$. This is because the Atlantic closure is only being compensated by the opening of the Pacific, with no other major oceans involved. This is an expression of the classical view of the Wilson cycle and Supercontinent cycle in which only two major oceans are involved, and one closes at the expense of the other.

The Novopangea scenario also shows similar values of divergence and convergence, in this case the Pacific closes at a rate of $7.1 \mathrm{~cm} \mathrm{yr}^{-1}$ while the Atlantic opens at a rate of $6.3 \mathrm{~cm} \mathrm{yr}^{-1}$. Here again, the scenario is mostly controlled by the opening and closure of two major oceans (the Pacific and the Atlantic) and therefore their divergence and convergence rates are almost balanced. However, this scenario also involves the opening of the East African Ocean $(2.4 \mathrm{~cm}$ $\left.\mathrm{yr}^{-1}\right)$ at the expense of the Indian ocean $\left(3.6 \mathrm{~cm} \mathrm{yr}^{-1}\right)$. 
In the Aurica scenario, both the Atlantic and the Pacific close; the Atlantic at a rate of $\sim 2.8 \mathrm{~cm}$ $\mathrm{yr}^{-1}$ and the Pacific at a rate of $7.2 \mathrm{~cm} \mathrm{yr}^{-1}$. This simultaneous closure has to be balanced by the development of the Pan-Asian Ocean, which opens at a rate of $9.6 \mathrm{~cm} \mathrm{yr}^{-1}$. This explains the high divergence rate of the Pan-Asian Ocean.

In the Amasia scenario only the Arctic Ocean closes, at a rate of $2.8 \mathrm{~cm} \mathrm{yr}^{-1}$. This is a result of both the small size of the Arctic basin and the fact that the timing of supercontinent formation was set to $200 \mathrm{Ma}$.

\section{Discussion}

The aim of this paper was to reconcile the scenarios of the formation of the next supercontinent as proposed by Scotese (2003), Nield (2007), Duarte et al. (2018) and Mitchell et al. (2012). Using GPlates, we have recreated the four scenarios from the same initial condition, leading to a new insight into the dynamics of Supercontinent and Wilson cycles. Due to the limited geological record the past supercontinents are poorly resolved, and the number of cycles are limited by the age of the Earth (and eventually by the emergence of plate tectonics). This is particularly true for the Wilson cycles because most of the oceanic basins are destroyed over the corresponding Supercontinent cycle(s). Studying these cycles from a known and excellently resolved starting position, i.e., the present-day, and running the current Supercontinent cycle forward has allowed us to better understand how these cycles work, how they interact with each other, and how they affect the configuration of the Earth's surface and the dynamics of the mantle. It should be noted that the degrees of freedom increase as we move forward into the Future and that it is why we have considered several end member scenarios.

There are several advantages and limitations to the approach we used. The main advantage is that we, for the first time, used a single software to simulate all the four proposed scenarios for the formation of the future supercontinents. This allowed us to carry out standardised models with similar initial and boundary conditions using the available GPlates data and capacities, providing us with new tools to discuss these scenarios in parallel and to better understand the geodynamic processes involved in each one of them. The objective of modelling the future is not just trying to guess what is going to occur but instead is a way of pushing the boundaries of our knowledge and trying to understand what the main processes operating at these longtime scales are.

Obviously, this approach also involves simplifications, leading to limitations. For example, we explored scenarios previously proposed by other authors that may not be up-to-date with new knowledge and techniques. They also often rely on only a few (and different) time slices. Using GPlates we were able to create scenarios that are continuous in space and time. We also assume that there is a Supercontinent cycle (even if not with a constant period), which implies that a new supercontinent should form within the next 200 - 300 Ma. But, the idea of a supercontinent, and the cycle itself, is an idealization (Bradley, 2011). It may well be that not all the continental masses come together in one Supercontinent cycle, as in the Amasia scenario. Furthermore, periods of Supercontinent assembly and break up are highly diachronic 
and often overlap (Bradley, 2011). The concept of Wilson cycles is also partially an idealization. It works well on interior oceanic basins that open and close during one Supercontinent cycle, such as the classical opening and closing of the Atlantic. However, it starts losing its meaning when we apply it to exterior oceans and oceans that do not precisely fit either the definition of exterior or interior (e.g., the Indian Ocean). Furthermore, some Wilson cycles may be incomplete, for example if a basin does not fully close, or if it closes in a subsequent Supercontinent cycle, in which case it would be severely delayed (e.g., in Pangea Ultima).

Another issue is subduction initiation in Atlantic-type oceans; we have just assumed that it can happen. This is a controversial topic and the driving mechanisms of subduction initiation are still fundamentally unknown (see, e.g., Duarte et al., 2013; Marques et al., 2014; Stern and Gerya, 2017). In any case, we have considered that passive margins are the most likely place for subduction zones to develop, either spontaneously or by invasion (Duarte et al., 2013), and even if they form intra-oceanically, they will quickly migrate (retreat) to passive margins (Whattam and Stern, 2011). This level of discussion, however, is out of the scope of this paper, but will be further investigated at a later date.

In our reasoning, it is also explicitly implied that oceanic lithosphere much older than $\sim 200 \mathrm{Ma}$ is gravitationally unstable and will be removed from the Earth's surface. This is supported by present-day observations of the seafloor age (Muller et al., 2008) and observation of the age of oceanic lithosphere in past cycles (Bradley, 2008; 2011). We have also assumed simple dynamics for mantle convection that considers major subduction systems as large-scale mantle downwellings and accounts for the existence of major mantle upwellings, defining two major convection systems. In our scenarios, these systems can split or merge, but the geometric constraints imposed by the Supercontinent cycle may force the Earth to be close to the twoconvection-system mode. Further work should be pursued in order to understand the feedbacks between mantle convection and Supercontinent cycles (Rolf et al., 2014: Coltice et al. 2012; Yoshida and Santosh, 2017).

Most of the scenarios do not fully incorporate dynamical constrains but are rather kinematical simulations of how the Earth may look like in the future. However, we have implicitly assumed some dynamic constrains, e.g., by discussing how mantle downwellings (subduction zones) and upwellings will interact in the future. We also assume that most of the plate motions are driven by the slab pull at subduction zones. Consequently, the geometry of subduction zones strongly controls the directions of plate movements and position of the continents.

In Table 2 we have plotted all of the continent's velocities for each of the scenarios. They all show average velocities of around $4 \mathrm{~cm} \mathrm{yr}^{-1}$, with the exception of Amasia $\left(2.13 \mathrm{~cm} \mathrm{yr}^{-1}\right)$. These velocities are close to the average paleo (Meso-Cenozoic) velocities reported by Young et al., (2018) of $6 \mathrm{~cm} \mathrm{yr}^{-1}$. Our lower average velocities mean that the timing of the next Supercontinent gathering may be overestimated in all the scenarios. Slightly higher velocities would probably result in a quicker supercontinent aggregation. For example, if the continent velocities were sped up, Amasia could form in 100 Ma or sooner. 
It should be noted that these values are also consistent with the convergence rates at subduction zones, which have a global value of $5.6 \mathrm{~cm} \mathrm{yr}^{-1}$ (Duarte et al., 2015). Convergence rates at subduction zones are an expression of the rate at which plates are consumed in the mantle. This makes sense and it means that in these scenarios plates (and therefore the continents) move on average at the velocity at which the slabs sink in the upper mantle.

Finally, it is worth remembering that these scenarios are useful idealizations based on concepts that describe end-members. For example, the classical introversion and extroversion scenarios were strongly conditioned by the misconception that Supercontinent cycles and Wilson cycles are the same thing. If this was the case, once a supercontinent, e.g., Pangea, breaks up it only has two options to reform the next supercontinent: by closing the Atlantic or by closing the Pacific. The problem is that this assumes that there were only two major continental masses travelling around the Earth. However, if more continents, and thus degrees of freedom, are considered, orthoversion and combination components are possible. One possibility is that whenever a supercontinent breaks up it may experience components of each of these scenarios during the corresponding Supercontinent cycle.

What is the use of modelling the remainder of the present Supercontinent cycle? Part of this work was motivated by ongoing parallel research on super-tidal cycles (Green et al., 2018), where it is suggested that the disposition of the continents and the geometry of the oceanic basins exert a first-order control on global tidal dynamics. Consequently, we hope to use the present scenarios as boundary condition in a global tidal model to further our understanding of the future Earth system.

\section{Acknowledgements}

H. S. Davies acknowledges funding from FCT (ref. UID/GEO/50019/2013 - Instituto Dom Luiz; FCT PhD grant ref. PD/BD/135068/2017). J. C. D. acknowledges an FCT Researcher contract, an exploratory project grant ref. IF/00702/2015, and the FCT project UID/GEO/50019/2013-IDL. J. A. M. G. acknowledges funding from the Natural Environmental Research Council through grants NE/F014821/1 and NE/I030224/1. Kara Matthews (Oxford University) provided invaluable support on using GPlates. We also acknowledge Dietmar Muller for bringing our team together. We would like to thank Pedro Miranda, Filipe Rosas, Pedro Terrinha, Wouter Schellart, Nicolas Riel, Jaime Almeida and Célia Lee for insightful discussions and for providing support related to several aspects of the work. Finally, we would like to thank the editor, Liviu Matenco, and Douwe van Hinsbergen and an anonymous reviewer for their constructive comments and suggestions that strongly contributed to improve this manuscript.

\section{References}

Boschman, L.M., \& Hinsbergen, D.J.J. Van, 2016. On the enigmatic birth of the Pacific Plate within the Panthalassa Ocean. Science Advances, 2(7), pp.1-6. Available at: DOI: 10.1126/sciadv.1600022. 
Bradley, D.C., 2008. Passive margins through earth history. Earth Science Reviews, 91(1-4), pp.1-26. Available at: http://dx.doi.org/10.1016/j.earscirev.2008.08.001.

Bradley, D.C., 2011. Secular trends in the geologic record and the supercontinent cycle. Earth Science Reviews, 108(1-2), pp.16-33. Available at: http://dx.doi.org/10.1016/j.earscirev.2011.05.003.

Burke, K. et al., 2008. Plume Generation Zones at the margins of Large Low Shear Velocity Provinces on the core - mantle boundary. Earth and Planetary Science Letters, 265(1-2), pp.49-60. Available at: https://doi.org/10.1016/j.epsl.2007.09.042.

Cande, S.C., \& Stegman, D.R., 2011. Indian and African plate motions driven by the push force of the Réunion plume head. Nature, 475(7354), pp.47 - 52. Available at: doi:10.1038/nature10174.

Cloos, M., 1993. Lithospheric buoyancy and collisional orogenesis: Subduction of oceanic plateaus, continental margins, island arcs, spreading ridges, and seamounts. Geological society of America Bulletin, 105(6), pp.715-737. Available at: https://doi.org/10.1130/00167606(1993)105<0715:LBACOS>2.3.CO;2.

Coltice, N., Rolf, T., Tackley, P. J., \& Labrosse, S., 2012. Dynamic Causes of the Relation between Area and Age of ocean Floor. Science, 336(6079), pp.335-338. Available at: DOI: 10.1126/science.1219120.

Dalziel, I.W.D., Mosher, S., \& Gahagan, L.M., 2000. Laurentia-Kalahari Collision and the Assembly of Rodinia. Journal of Geology, 108(5), pp.499-513. Available at: DOI: $10.1086 / 314418$.

Dalziel, I.W.D., et al., 2013. The Scotia Arc: Genesis, Evolution, Global Significance. Annual Review of Earth and Planetary Sciences, 41, pp.767-793. Available at: doi: 10.1146/annurev-earth-050212-124155.

Dewey, J., \& Spall, H., 1975. Pre - Mesozoic plate tectonics: How far back in Earth history can the Wilson Cycle be extended? Penrose Conference report, 3(8), pp.422-424. Available at: https://doi.org/10.1130/0091-7613(1975)3<422:PPTHFB>2.0.CO;2.

Duarte, J.C., et al., 2013. Are subduction zones invading the Atlantic? Evidence from the southwest Iberia margin. Geology, 41(8), pp.839-842. Available at: https://doi.org/10.1130/G34100.1.

Duarte, J.C., Schellart, W.P., \& Cruden, A.R., 2015. How weak is the subduction interface? Geophysical research letters, 42 (8), pp. 2664-2673. Available at: https://doi.org/10.1002/2014GL062876. 
Duarte, J.C., Schellart, W.P., \& Rosas, F.M., 2018. The future of Earth's oceans: consequences of subduction initiation in the Atlantic and implications for supercontinent formation. Geological Magazine, 155(1), pp.45-58. Available at:

DOI: $10.1017 / \mathrm{S} 0016756816000716$.

Eagles, G., \& Jokat, W. 2014. Tectonic reconstructions for the Paleobathymetry in Drake Passage. Tectonophysics, 611, pp. 28 - 50. Available at: http://dx.doi.org/10.1016/j.tecto.2013.11.021.

Forsyth, D., \& Uyeda, S., 1975. On the Relative Importance of the Driving Forces of Plate Motion. Geophysical Journal of the Royal Astronomical Society, 43(1), pp.163-200.

Available at: https://doi.org/10.1111/j.1365-246X.1975.tb00631.x

Golonka, J., 2007. Late Triassic and Early Jurassic palaeogeography of the world. Palaeogeography, Palaeoclimatology, Palaeoecology, 244, pp.297-307. Available at: https://doi.org/10.1016/j.palaeo.2006.06.041

Granot, R., 2016. Palaeozoic oceanic crust preserved beneath the Eastern Mediterranean. Nature geoscience, 9(9), pp.701-705. Available at: DOI: 10.1038/NGEO2784.

Green, J.A.M., Molloy, J.L., Davies, H.S., \& Duarte, J.C., 2018. Is there a tectonically driven super-tidal cycle? Geophysical research letters, 45 (8), Available at: https://doi.org/10.1002/2017GL076695.

Hatton, C.J., 1997. The Superocean cycle. S. Afr. J. Geology, 100(4), pp. 301-310.

Hoffman, P., 1999. The break-up of Rodinia, birth of Gondwana, true polar wander and the snowball Earth. Journal of African Earth Sciences, 28(1), pp.17-33. Available at: 10.1016/S0899-5362(99)00018-4

Iaffaldano, G., Davies, D.R., \& DeMets, C. 2018. Indian Ocean floor deformation induced by the Reunion plume rather than the Tibetan Plateau. Nature Geoscience, 11, pp. $362-366$. Available at: $\underline{10.1038 / \mathrm{s} 41561-018-0110-\mathrm{z} \text {. }}$

Le Pichon, X., 1968. Sea-Floor Spreading and Continental Drift. Journal of Geophysical Research, 73(12), pp.3661-3697. Available at: https://doi.org/10.1029/JB073i012p03661.

Marques, F.O., et al., 2014. Subduction initiates at straight passive margins. Geology, 42(4) pp.331-334. Available at: doi:10.1130/G35246.1.

Matthews, K.J., et al., 2016. Global plate boundary evolution and kinematics since the late Paleozoic Global plate boundary evolution and kinematics since the late Paleozoic. Global and Planetary Change, 146, pp.226-250. Available at:

http://dx.doi.org/10.1016/j.gloplacha.2016.10.002. 
Mckenzie, D.P., \& Parker, R.L., 1967. The North Pacific: an Example of Plate Tectonics on a Sphere. Nature, 216, pp.1226-1280. Available at: http://dx.doi.org/10.1038/2161276a0.

Meert, J.G., 2014. Geoscience Frontiers Strange attractors, spiritual interlopers and lonely wanderers: The search for pre-Pangean supercontinents. Geoscience Frontiers, 5(2), pp.155166. Available at: http://dx.doi.org/10.1016/j.gsf.2013.12.001.

Merdith, A.S., et al., 2017. A Full-Plate Global Reconstruction of the Neoproterozoic. Gondwana Research, 50, pp.84-134. Available at: http://dx.doi.org/10.1016/j.gr.2017.04.001.

Mitchell, R.N., Kilian, T.M., \& Evans, D.A.D., 2012. Supercontinent cycles and the calculation of absolute palaeolongitude in deep time. Nature, 482(7384), pp.208-211. Available at: http://dx.doi.org/10.1038/nature10800.

Mueller, S., \& Phillips, R.J., 1991. On the initiation of subduction. American Geophysical union, 96(B1), pp.651-665. Available at: https://doi.org/10.1029/90JB02237.

Muller, D.M., et al., 2008. Long-Term Sea-Level Fluctuations Driven by Ocean Basin Dynamics. Science, 319(5868), pp.1357-1362. Available at: $10.1126 /$ science.1151540.

Murphy, J.B., \& Nance, R.D., 2003. Do supercontinents introvert or extrovert?: Sm-Nd isotopic evidence. Geology, 31(10), pp.873-876. Available at:

https://doi.org/10.1130/G19668.1.

Murphy, J.B., \& Nance, R.D., 2005. Do Supercontinents turn inside-in or inside-out? International Geology Review, 47(6), pp.591-619. Available at: https://doi.org/10.2747/0020$\underline{6814.47 .6 .591}$

Murphy, J.B., \& Nance, R.D., 2008. The Pangea conundrum. Geology, 36(9), pp.703-706. Available at: 10.1130/G24966A.1.

Murphy, J.B., Nance, R.D., \& Cawood, P., 2009. Contrasting Modes of Supercontinent Formation and the Conundrum of Pangea. Gondwana Research, 15(3-4), pp.408-420. Available at: http://dx.doi.org/10.1016/j.gr.2008.09.005.

Nance, R.D., Worsley, T.R., \& Moody, J.B., 1988. The Supercontinent Cycle. Scientific American, 259(1), pp.72-79.

Nance, R.D., et al., 2012. A brief history of the Rheic Ocean. Geoscience Frontiers, 3(2), pp.125-135. Available at: https://doi.org/10.1016/j.gsf.2011.11.008.

Nield, T. 2007, Supercontinent: London, Granta Books, 287 p. 
Qin, X., et al., 2012. The GPlates Geological Information Model and Markup Language. Geoscientific Instrumentation Methods and Data Systems, 1, pp.111-134. Available at: 10.5194/gi-1-111-2012.

Rogers, J.J.W., \& Santosh, M., 2003. Supercontinents in Earth History. Gondwana Research, 6(3), pp.357-368. Available at: https://doi.org/10.1016/S1342-937X(05)70993-X.

Rolf, T., Coltice, N., \& Tackley, P.J., 2014. Statistical cyclicity of the supercontinent cycle. Geophysical research letters, 41(7), pp.2351-2358. Available at: https://doi.org/10.1002/2014GL059595.

Schellart, W.P., \& Rawlinson, N., 2010. Tectonophysics Convergent plate margin dynamics: New perspectives from structural geology, geophysics and geodynamic modelling. Tectonophysics, 483(1-2), pp.4-19. Available at: http://dx.doi.org/10.1016/j.tecto.2009.08.030.

Schellart, W.P., et al., 2007. Evolution and diversity of subduction zones controlled by slab width. Nature, 446, pp.1-4. Available at: http://dx.doi.org/10.1038/nature05615.

Schellart, W.P., Stegman, D.R., \& Freeman, J., 2008. Global trench migration velocities and slab migration induced upper mantle volume fluxes: Constraints to find an Earth reference frame based on minimizing viscous dissipation. Earth Science Reviews, 88(1-2), pp.118-144. Available at: https://doi.org/10.1016/j.earscirev.2008.01.005.

Scotese, C.R., 1991. Jurassic and Cretaceous plate tectonic reconstructions.

Palaeogeography, Palaeoclimatology, Palaeoecology, 87(1-4), pp.493-501. Available at: https://doi.org/10.1016/0031-0182(91)90145-H.

Scotese, C.R. 2003, Palaeomap project: http://www.scotese.com/earth.htm (Accessed on 25/10/17).

Scotese, C.R. 2009, Late Proterozoic plate tectonics and palaeogeography: A tale of two supercontinents, Rodinia and Pannotia. Geological Society London Special Publications, 326(1), pp.67-83. Available at: doi:10.1144/SP326.4

Silver, P.G. \& Behn, M.D., 2008. Intermittent Plate Tectonics? Science, 319(5859), pp.8587. Available at: $10.1126 /$ science. 1148397.

Stampfli, G.M., \& Borel, G.D., 2002. A plate tectonic model for the Paleozoic and Mesozoic constrained by dynamic plate boundaries and restored synthetic oceanic isochrons. Earth and Planetary Science Letters, 196(1-2), pp.17-33. Available at: https://doi.org/10.1016/S0012821X(01)00588-X.

Stern, R.J. \& Gerya, T., 2017. Subduction initiation in nature and models: A Review. Tectonophysics. Available at: http://dx.doi.org/10.1016/j.tecto.2017.10.014. 
812 Thorkelson, D.J. 1996. Subduction of diverging plates and the principles of slab window

813 formation. Tectonophysics, 255(1-2), pp.47-63. Available at: https://doi.org/10.1016/0040-

$814 \quad$ 1951(95)00106-9.

815 Torsvik, T.H., et al., 2010. Diamonds sampled by plumes from the core - mantle boundary.

816 Nature, 466(7304), pp.352-355. Available at: http://dx.doi.org/10.1038/nature09216.

817 Torsvik, T.H., et al., 2016. Earth Evolution and Dynamics - A tribute to Kevin Burke.

818 Canadian Journal of Earth Sciences, 53(11), pp.1073-1087. Available at:

819 https://doi.org/10.1139/cjes-2015-0228.

820 Van der Meer, D.G., et al., 2012. Intra-Panthalassa Ocean subduction zones revealed by fossil arcs and mantle structure. Nature Geoscience, 5, pp.215-219. Available at: DOI: 10.1038/NGEO1401.

Wegener, A. 1912. Die Entstehung der Kontinente (The formation of the continents).

Whattam, S.A., \& Stern, R.J., 2011. The 'subduction initiation rule': a key for linking ophiolites, intra-oceanic forearcs, and subduction initiation. Contrib. Mineral Petrol, 162(5), pp.1031-1045. Available at: doi: 10.1007/s00410-011-0638-z.

Wilson, J.T., 1965. A new class of faults and their bearing on Continental Drift. Nature, 207(4995), pp.343-347. Available at: http://dx.doi.org/10.1038/207343a0.

830 Wilson, J.T., 1966. Did the Atlantic close and then re-open? Nature, 211, pp.676-681.

831 Available at: http://dx.doi.org/10.1038/211676a0.

832 Wright, J.E., \& Wyld, S.J., 2011. Late cretaceous subduction initiation on the eastern margin 833 of the Caribbean-Colombian Oceanic Plateau: One Great Arc of the Caribbean? Geosphere, 7 834 (2), pp. 468-493. Available at: https://doi.org/10.1130/GES00577.1.

835 Yoshida, M., 2016. Formation of a future supercontinent through plate motion - driven flow 836 coupled with mantle downwelling flow. The Geological Society of America, 44(9), pp.755-

837 758. Available at: https://doi.org/10.1130/G38025.1

838 Yoshida, M., \& Santosh, M., 2011. Future supercontinent assembled in the northern 839 hemisphere. Terra Nova, 23(5), pp.333-338. Available at: https://doi.org/10.1111/i.1365$840 \quad$ 3121.2011.01018.x.

841 Yoshida, M., \& Santosh, M., 2017. Geoscience Frontiers Voyage of the Indian subcontinent 842 since Pangea breakup and driving force of supercontinent cycles: Insights on dynamics from 843 numerical modeling. Geoscience Frontiers, pp.1-14. Available at:

844 https://doi.org/10.1016/j.gsf.2017.09.001. 
845 Young, A., et al., 2018. Global kinematics of tectonic plates and subduction zones since the 846 late Paleozoic Era, Geoscience Frontiers, Available at: doi: 10.1016/j.gsf.2018.05.011. 


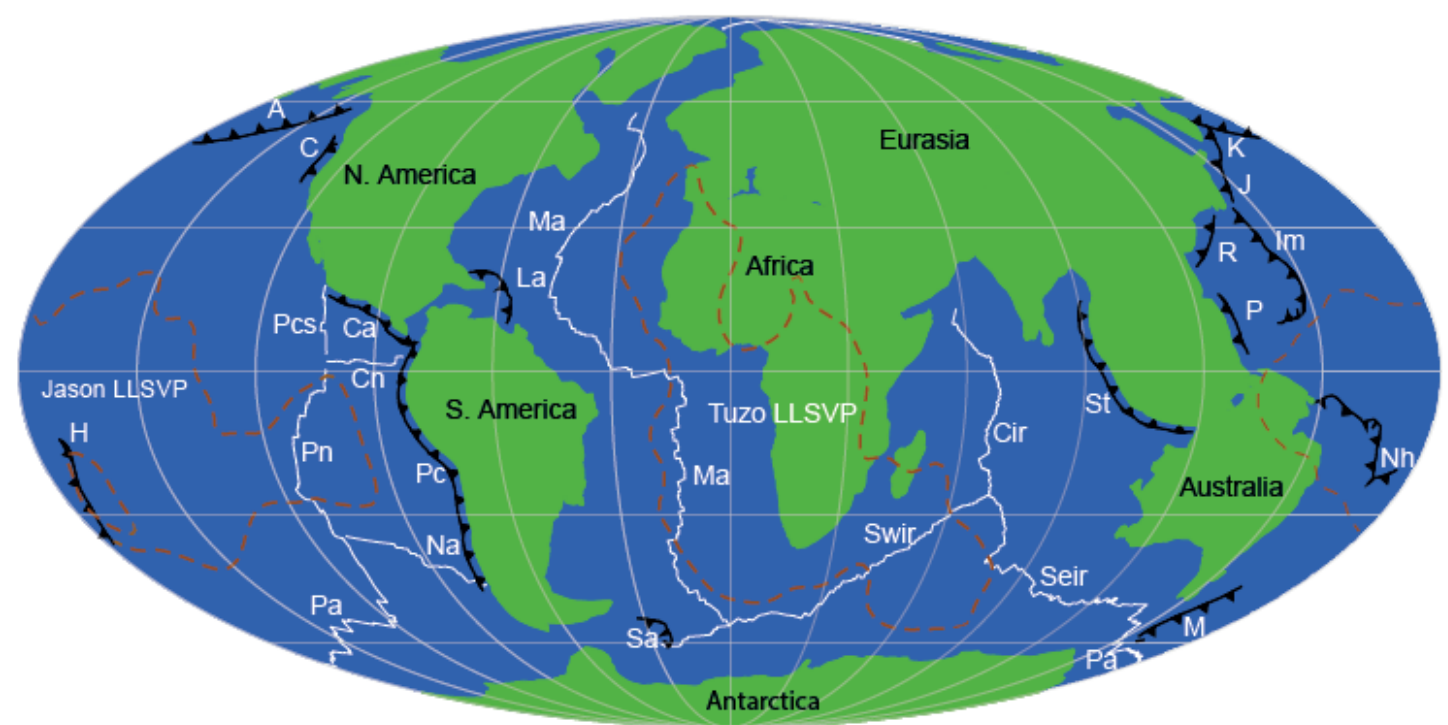

850 Figure 1. GPlates set-up of present-day Earth used as the initial condition for each of the future 851 scenarios. White lines represent mid-ocean ridges: Ma, Mid-Atlantic ridge; Swir, SW Indian 852 Ridge; Cir, Central Indian ridge; Seir, SE Indian Ridge; Pa, Pacific-Antarctic spreading centre; 853 Na, Nazca-Antarctic spreading center; Pn, Pacific-Nazca spreading center; Cn, Cocos-Nazca 854 spreading centre; Pcs, Pacific-Cocos spreading center; Ar, Arctic Ridge. Black lines represent 855 subduction zones: A, Aleutian trench; Ca, Central American trench; C, Cascadia subduction 856 zone; H, Hikurangi trench; Im, Izu-Marianas trench; J, Japan trench; K, Kurile Trench; La, 857 Lesser Antilles arc; M, Macquarie subduction zone; Nh, New Hebrides subduction zone; P, 858 Philippine trench; R, Ryukyu subduction zone; Sa, Scotia arc; St, Sumatra trench. Black arrows 859 represent drift directions for each continent from Schellart et al. (2007). Brown dashed lines 860 represent the extents of the LLSVPs discussed in Torsvik et al. (2016), marked above as Tuzo 861 and Jason. 

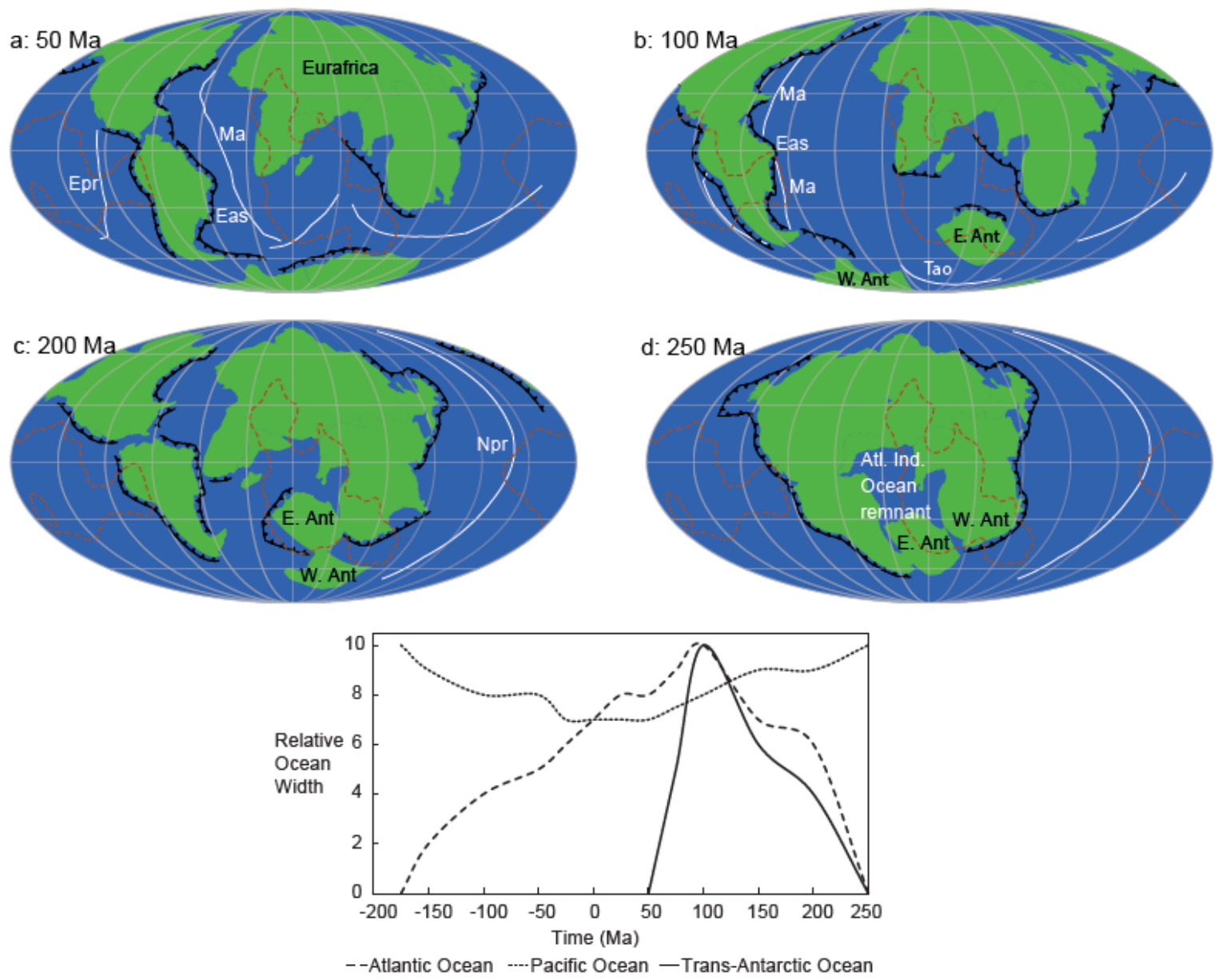

864 Figure 2a-e. (a-d): A map of the development of Pangea Ultima, showing $50 \mathrm{Ma}, 100 \mathrm{Ma}, 200$

$865 \mathrm{Ma}$ and $250 \mathrm{Ma}$. Speculative subduction zones and ridges are represented in red and white, 866 respectively. Brown represents LLSVP extents as in Torsvik et al. (2016). The centre point of 867 the map is along the Greenwich meridian $\left(0^{\circ}\right)$. Eas, East American subduction zone; Ma, Mid868 Atlantic ridge; E. Ant, East Antarctica; W. Ant, West Antarctica. (e): An illustration of the 869 development of the supercontinent Pangea Ultima since the break-up of Pangaea. The major 870 oceans of the Pacific, Atlantic, and Trans-Antarctic are presented. Other oceans and seas have 871 been omitted (see figure 2a-d). The oceans widths have been normalized between values of 0 872 and 10, representing the smallest and largest extent of each ocean. 

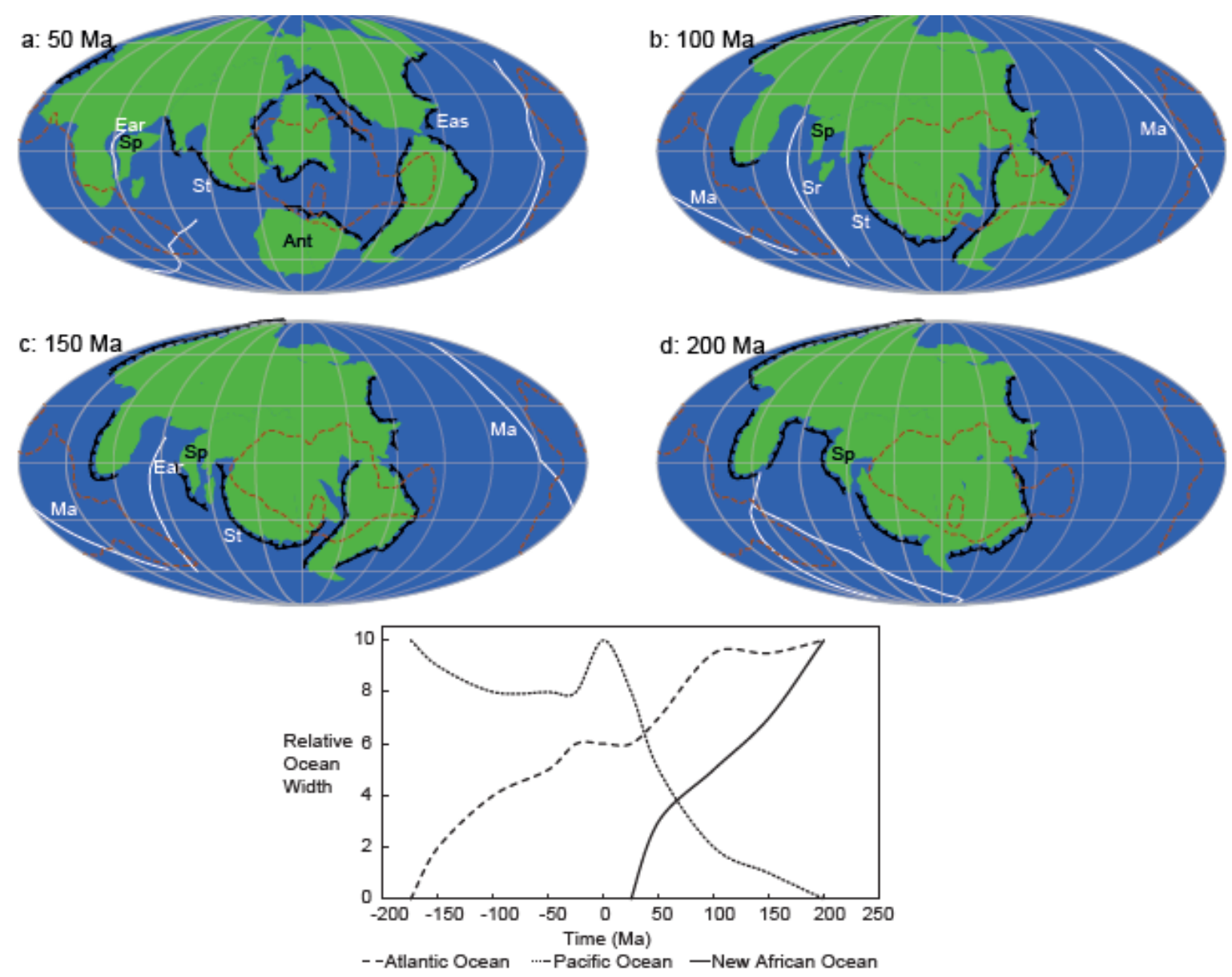

875 Figure 3a-e. (a-d): Maps of Novopangea from top left to bottom right $50 \mathrm{Ma}, 100 \mathrm{Ma}, 150 \mathrm{Ma}$ 876 and $200 \mathrm{Ma}$ respectively. Speculative subduction zones and ridges are represented in red and 877 white respectively. Yellow represents LLSVP extents as in Torsvik et al. (2016). The centre 878 point of this map is along the international date line $\left(180^{\circ}\right)$. Ear, East African rift; Sp, Somalia 879 plate; St, Sumatra trench; Ant, Antarctica; Eas, East American subduction zone; Ma, Mid 880 Atlantic. (e): A graphical illustration of the development of the supercontinent of Novopangea. 881 The major oceans of the Pacific, Atlantic and New African are presented. Other oceans and seas have been omitted (see figure 3a-d). 

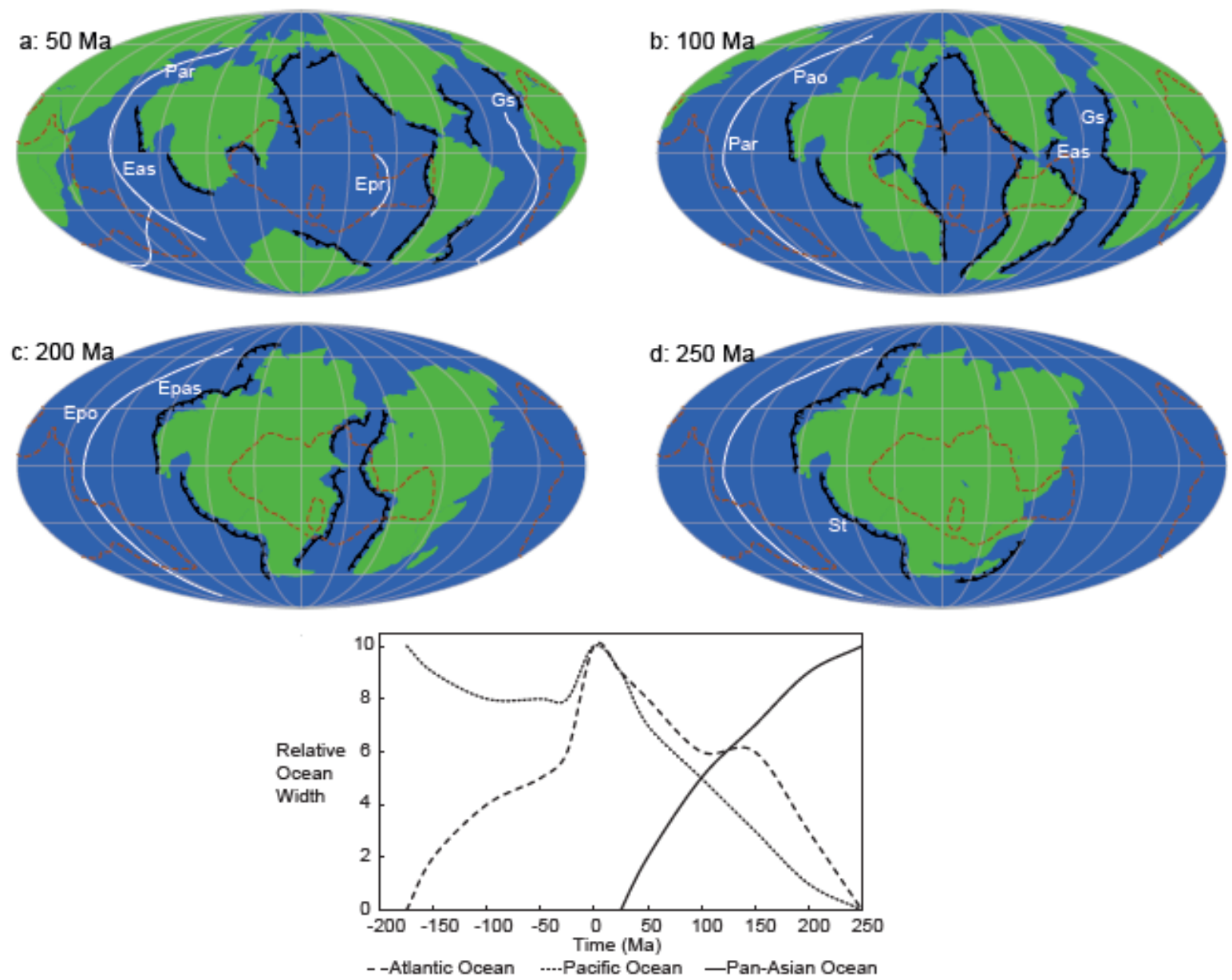

884 Figure 4a-e. (a-d): Maps of Aurica from top left to bottom right $50 \mathrm{Ma}, 100 \mathrm{Ma}, 200 \mathrm{Ma}$ and $250 \mathrm{Ma}$, respectively. Speculative subduction zones and ridges are represented in red and white, respectively. Yellow represents LLSVP extents as in Torsvik et al. (2016). The centre point of this map is along the international date line $\left(180^{\circ}\right)$. Par, Pan-Asian rift, Epr, East Pacific rise; Eas, East American subduction zone; Gs, Gibraltar subduction zone; Epas, East Pan-Asian subduction zone (e): A graphical illustration of the development of the supercontinent of Aurica. The major oceans of the Pacific, Atlantic and Pan-Asian are presented. Other oceans and seas have been omitted. 

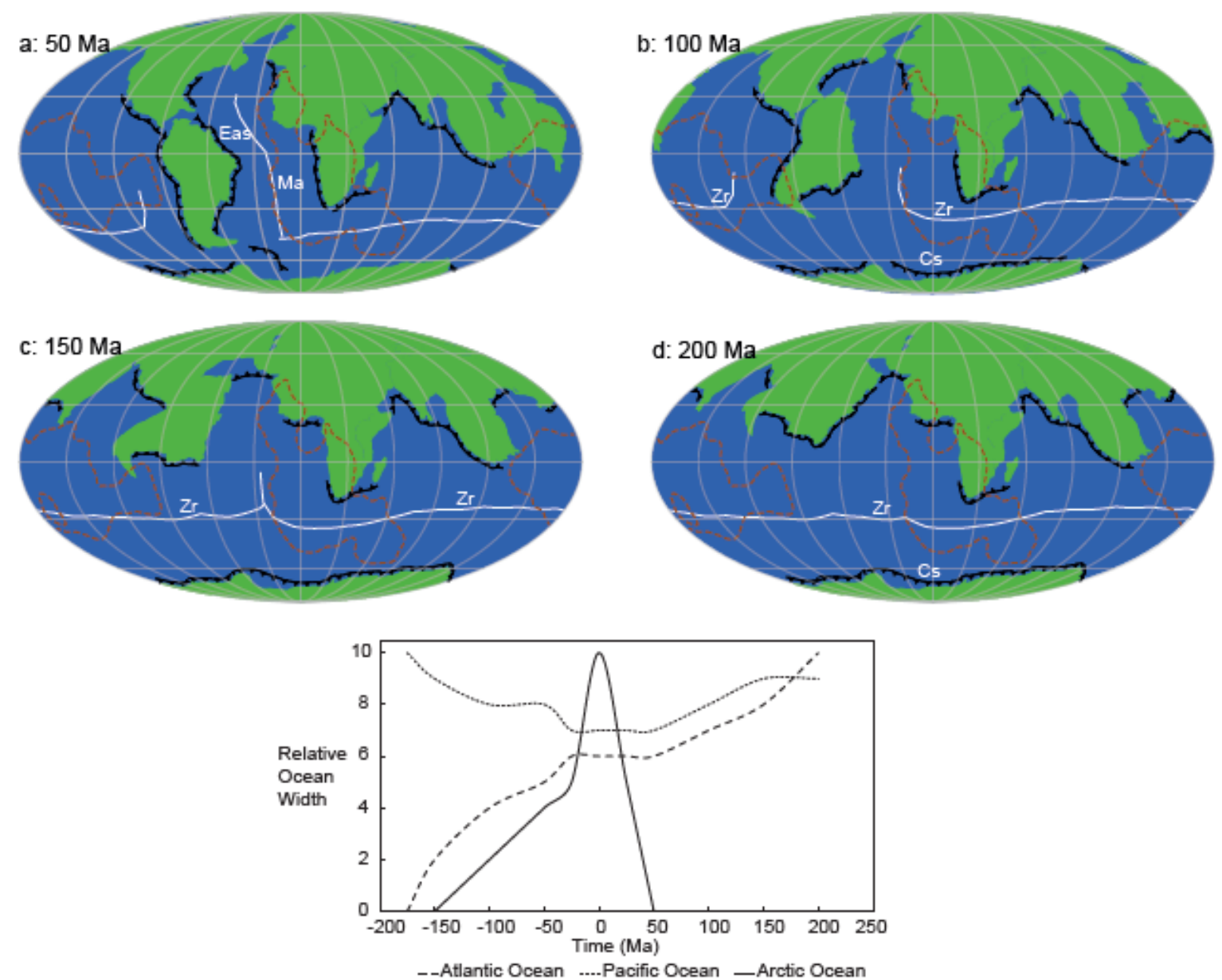

893 Figure 5a-e. (a-d): Maps of Amasia from top left to bottom right $50 \mathrm{Ma}, 100 \mathrm{Ma}, 150 \mathrm{Ma}$ and $200 \mathrm{Ma}$, respectively. Speculative subduction zones and ridges are represented in red and white, respectively. Yellow represents LLSVP extents as in Torsvik et al. (2016). The centre point of this map is along the Greenwich meridian $\left(0^{\circ}\right)$. Eas, East American subduction zone; Ma, Mid-Atlantic ridge; Zr, Zonal ridge; Cs, Circumferential Antarctic subduction zone (e): A graphical illustration of the development of the supercontinent of Amasia. The major oceans of the Pacific, Atlantic and Arctic are presented. Other oceans and seas have been omitted. 


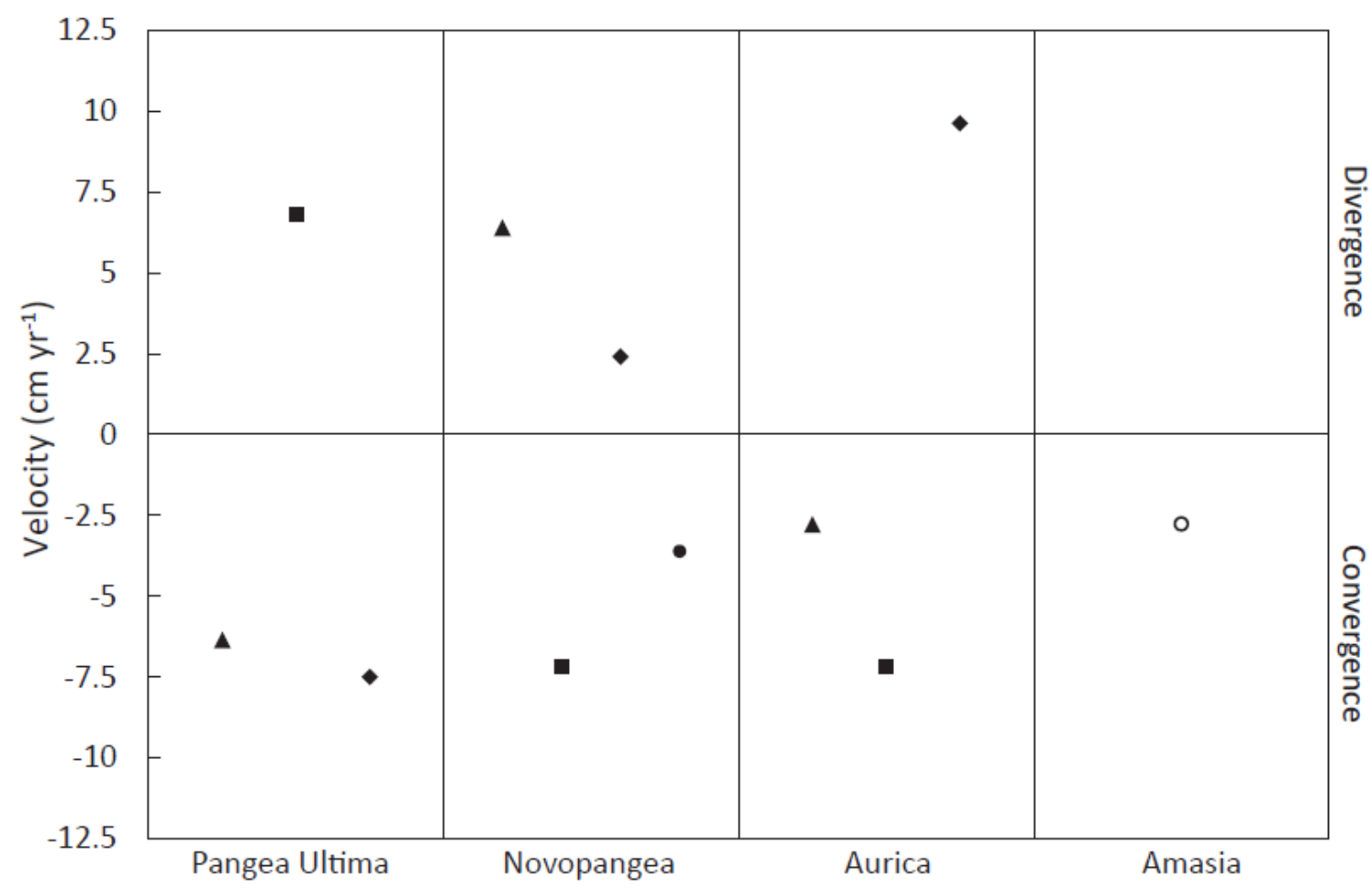

901

902 Figure 6. Divergence (positive) and Convergence (negative) rates in $\mathrm{cm} \mathrm{yr}^{-1}$ for the Atlantic 903 ocean (triangles), Pacific ocean (squares), Indian ocean (filled circles), Arctic ocean (empty 904 circles), and new oceans (Trans-Antarctic - Pangea Ultima, East African - Novopangea, and 905 Pan-Asia - Aurica)(Diamonds). 